\title{
GESTÃO DA INFORMAÇÃO EM AMBIENTES ORGANIZACIONAIS: EM FOCO O SETOR TÊXTIL E DE VESTUÁRIO
}

\section{GESTIÓN DE LA INFORMACIÓN EN AMBIENTES ORGANIZACIONALES: ENFOQUE EN EL SECTOR TEXTIL Y DE CONFECCIÓN}

Juliana Cardoso dos Santos - julimath21@gmail.com Doutoranda em Ciência da Informação pela Universidade Estadual Paulista (Unesp - Marília).

Marta Lígia Pomim Valentim - valentim@marilia.unesp.br Doutora em Ciências da Comunicação pela Universidade de São Paulo (USP). Professora da Universidade Estadual Paulista (Unesp - Marília).

\begin{abstract}
RESUMO
Introdução: A globalização, competitividade e a necessidade em se obter informações direcionadas ao negócio com valor agregado são fatores determinantes para as organizações gerarem diferenciais competitivos. Nesse contexto, as organizações podem ser vistas como sistemas que geram, processam e aplicam informações que, por sua vez, podem ser transformadas em ações estratégicas.

Objetivo: Apresenta referencial teórico sobre o potencial da gestão da informação como instrumento gerador de competitividade para o setor têxtil e de vestuário.

Metodologia: Realizou-se um ensaio de cunho teórico e de caráter descritivo exploratório enfocando a gestão da informação e sua contribuição para a geração de diferenciais competitivos.

Resultados: Infere-se, a partir da análise da literatura, que a competitividade organizacional está imbricada aos fazeres da organização, bem como possui potencial competitivo imensurável para apoiar o desenvolvimento do setor têxtil e de vestuário, sendo relevante e indispensável o uso da gestão da informação para apoiar as estratégias competitivas destes segmentos econômicos.

Conclusões: A partir da análise de conceitos e definições obteve-se uma visão aprofundada sobre a temática, evidenciando que a informação é insumo fundamental para a geração de diferenciais competitivos, bem como instiga novas reflexões sobre a aplicação da gestão da informação em organizações do setor têxtil e de vestuário.
\end{abstract}


Palavras-Chave: Gestão da informação. Competitividade Organizacional. Diferenciais Competitivos. Setor têxtil e vestuário. Moda.

\section{INTRODUÇÃO}

O ambiente empresarial requer o acesso rápido e eficaz à informação, uma vez que atualmente antecipar resultados e tendências e prospectar mercados potenciais se constituem em recursos estratégicos para as organizações. A informação alicerça diferentes ações organizacionais e, em especial, apoia os sujeitos organizacionais no intuito de prepará-los a assumir desafios, adquirir competências, habilidades, aptidões e atitudes visando a geração de diferenciais competitivos à organização.

A informação voltada ao negócio está diretamente relacionada ao modo de pensar e produzir um novo produto, melhorar um processo industrial ou prestar um serviço ao cliente, assim atua em diferentes contextos organizacionais, propiciando a melhoria da qualidade e da produtividade de processos e fluxos organizacionais, ou seja, é insumo para o desenvolvimento de qualquer setor industrial.

A informação é fator tão importante para a organização quanto o capital humano. Gerenciar informação - aqui compreendida como uma atividade que congrega: prospecção, monitoramento, análise, organização, armazenamento e disseminação de informações pertinentes ao negócio -, bem como contextualizá-la para facilitar os fluxos e processos organizacionais como, por exemplo, o processo decisório, se constituem em ações informacionais que contribuem significativamente para que as organizações atuem com segurança frente ao mercado em que atuam.

O presente ensaio teórico teve como objetivo estudar os fenômenos geradores de diferenciais competitivos, no âmbito da Gestão da Informação (GI) voltado ao setor industrial têxtil e de vestuário, uma vez que é um segmento altamente competitivo, e que possui um ciclo 
informacional dinâmico, assim como necessita de a antecipação informacional para poder oferecer produtos diferenciados, ou seja, são informações com alto valor agregado que objetivam a manutenção das empresas no mercado em que atuam.

\section{PROCEDIMENTOS METODOLÓGICOS}

Este ensaio teórico configura-se como descritivo exploratório, por tentar descrever características dos fenômenos estudados estabelecendo relações entre a GI e a competitividade do setor industrial têxtil e de vestuário.

Segundo Triviños (1987) estudos descritivos exploratórios visam aprofundar o conhecimento sobre determinada realidade, portanto, o foco foi desenvolver uma revisão bibliográfica sobre as temáticas que sustentam a discussão aqui proposta com o intuito de aprofundar o conhecimento sobre esta temática, com base em um contexto complexo. Este ensaio não finda os esforços em compreender as questões abordadas, mas sim realiza diálogos com base na literatura consultada almejando reflexões visando uma melhor compreensão do objeto e fenômenos investigados.

\section{INFORMAÇÃO}

Informação e conhecimento são elementos que se caracterizam como potencialmente competitivos, visto que têm o poder de gerar progresso econômico, tecnológico, industrial, isto é, os empresários têm na informação e no conhecimento um significativo elemento de trabalho.

McGee e Prusak (1994, p.45) consideram que a informação afeta o estabelecimento da estratégia da organização, "[...] [a] informação e a tecnologia de informação tem sido utilizadas com significativa vantagem competitiva na execução de processos vitais de negócios [...]", visto que 
as instabilidades oriundas da competitividade permeiam as organizações de diferentes segmentos econômicos.

A informação pode reduzir ou amenizar incertezas, portanto, uma vez que a informação e o conhecimento passam a ser compreendidos como elementos estratégicos, e que possibilitam a geração de diferenciais competitivos, a organização necessita gerenciá-los da mesma maneira que gerencia os recursos humanos, financeiros e materiais (CIANCONI, 1999).

A informação é insumo para construir significado e conhecimento, sendo também um ato de instrução, indagação, investigação, notícia. Ela pode se expandir, ser completada, substituída, transportada, difundida e compartilhada. Pode ser considerada um produto ou mercadoria, porquanto ela impulsiona o crescimento da sociedade, e o mercado está exigindo que as organizações sejam capazes de produzir bens e serviços baseados em informação (TARAPANOFF et al., 2000).

Para Buckland (1991, tradução nossa, grifo nosso) a informação pode ser vista sob três aspectos: informação como processo que alimenta o processo cognitivo, isto é, alimenta o conhecimento existente de um indivíduo de modo que o conhecimento possa ser modificado. A informação como conhecimento se constitui no conhecimento de mundo que o indivíduo possui adquirido ao longo de sua existência [imaterial], por meio das experiências vivenciadas. A informação como coisa é a informação contida em um determinado suporte, ou seja, é aquela que está explicitada, sistematizada, documentada e, portanto, tangível [material].

Inovar é buscar por algo novo e a informação é subsídio para se obter isso, porquanto é notória sua importância para a atividade inovativa. Diferentes autores a consideram uma ferramenta e/ou insumo que permeia as ações organizacionais, propiciando a previsão de tendências e se constituindo em subsídio essencial para a tomada de decisão. 
Para Valentim (1994, grifo nosso) a informação pode ser classificada em:

- Estruturadas - informações que já sofreram algum tipo de organização e tratamento, constituindo-se em bancos e bases de dados internos e externos à organização, passíveis de acesso;

- Estruturáveis - informações disponíveis internamente à organização, mas os dados e as fontes dos dados não estão organizados e tratados para serem acessados de forma lógica;

- Não Estruturadas - informações disponíveis externamente à organização, mas que não estão organizadas e tratadas, portanto de difícil acesso e recuperação.

A informação pode ser apropriada por um determinado indivíduo, assim somente se constitui "informação", se o sujeito cognoscente compreende seu significado e possui condições para apropriá-la, por meio de uma mediação/interação. Evidencia-se que diferentes autores defendem significados distintos para o termo informação, ou seja, seu conceito não apresenta consenso quanto ao seu significado, visto que é definida de acordo com o contexto e finalidade com que está sendo empregada. Para Morin (1999, p.68)

Aprender não é somente adquirir um savoir-faire, mas também saber como fazer para adquirir saber; pode ser a aquisição de informações; pode ser a descoberta de qualidades ou propriedades inerentes a coisas ou seres; pode ser a descoberta de uma relação entre dois acontecimentos, ou ainda, a descoberta da ausência de ligação entre eles.

Nessa perspectiva, infere-se que a informação é entendida como um processo que modifica estruturas, que pode ser assimilada e internalizada e é imprescindível para o desenvolvimento das organizações, pois o sujeito organizacional necessita ter consciência sobre o que de fato sabe.

A informação é complexa e no ambiente organizacional pode ter várias aplicabilidades e denominações como apresenta Valentim (2006): 
informação estratégica; informação voltada ao negócio; informação financeira; informação comercial; informação sobre gestão, informação tecnológica; informação geral que, por sua vez, podem se apresentar de forma estruturada, estruturável ou não estruturada, mas que fazem parte do processo e contribuem para o desenvolvimento das organizações, desde que geridas de modo eficiente.

A informação deve ser compreendida como um elemento essencial para o setor empresarial, assim como tanto a informação quanto o conhecimento podem ser considerados um capital simbólico, pois o conhecimento será sempre tácito, mas uma vez que o sujeito o explicita, mesmo que parcialmente, este se transforma em informação.

\section{GESTÃO DA INFORMAÇÃO EM ORGANIZAÇÕES}

As incertezas e as instabilidades oriundas da competitividade que ocorre no cenário contemporâneo fazem com que as organizações busquem informações sobre 0 ambiente organizacional, visando fomentar a eficácia das decisões. Realizar a Gl efetivamente passou a ser uma atividade essencial à sobrevivência do setor industrial, à medida que estes percebem sua importância como diferencial estratégico, porquanto as organizações que mais bem gerenciarem suas informações, tanto do ambiente interno quanto do ambiente externo, terão mais possibilidades de identificar as oportunidades e as ameaças do mercado.

Em geral, uma organização não teria condições de atuar sem informação de diferentes tipos e naturezas, influência da revolução informacional, cujas características marcantes são a velocidade e a competitividade. Nesse sentido, obter informação confiável, no momento certo e com valor agregado é essencial para o estabelecimento de ações estratégicas organizacionais. Dessa maneira, esse contexto depende de recursos informacionais distintos, assim como de recursos materiais e humanos e, portanto, necessitam ser gerenciadas 
eficientemente para auxiliar as organizações na melhoria da qualidade e produtividade. Por essas razões, a informação deve ser trabalhada nessa ótica e ser construída e reconstruída a todo instante tendo como base 0 conhecimento científico, tecnológico, estratégico e organizacional.

Davenport e Prusak (1998) afirmam que o ambiente de informação em sua totalidade leva em conta os valores e as crenças organizacionais sobre a informação. Nesse sentido, a maneira como as pessoas realmente geram e usam a informação e o que fazem dela, as distintas problemáticas que podem interferir na interação informacional existem e estão presentes no cotidiano organizacional, visto que a gestão é sempre uma atividade que envolve planejamento, direção, coordenação e controle, ou seja, a gestão estabelece princípios, políticas, planos, funções e atividades visando à eficiência para atingir os objetivos e metas organizacionais.

O mercado contemporâneo exige que as organizações se transformem de tal maneira, que elas possam ser capazes de produzir bens e serviços para atender as necessidades dos clientes internos e externos. Portanto, a GI deve estar apta para atender os diversos níveis hierárquicos organizacionais, ou seja, estratégico, tático e operacional, contemplando diferentes níveis de acesso e se fundamentando na utilização de modelos, métodos e técnicas para desenvolver e processar informações que possuam relevância para a organização. Entende-se a GI como:

[...] um conjunto de estratégias que visa identificar as necessidades informacionais, mapear os fluxos formais de informação nos diferentes ambientes da organização, assim como sua coleta, filtragem, análise, organização, armazenamento e disseminação, objetivando apoiar o desenvolvimento das atividades cotidianas e a tomada de decisão no ambiente corporativo. (VALENTIM, 2004, p.1).

Um dos principais objetivos da $\mathrm{Gl}$ é potencializar os recursos informacionais existentes em uma determinada organização, de maneira 
a apoiar e subsidiar as atividades desenvolvidas no cotidiano, apoiar o processo decisório, bem como ampliar a capacidade e aprendizagem organizacional, de modo que a organização se adapte as mudanças que ocorrem no ambiente (TARAPANOFF, 2001).

No cenário globalizado a agilidade referente ao acesso, recuperação, tratamento e disseminação da informação potencializa as ações da organização frente aos clientes e concorrentes, tornando a informação um diferencial competitivo importante. Contudo algumas organizações, ainda, desconhecem suas próprias necessidades informacionais. A GI apoia-se nos fluxos formais (conhecimento explícito), e enfoca as informações registradas, constituindo-se em ativos informacionais tangíveis que são utilizados na maioria das organizações, pois tendem a se preocupar com as informações geradas, recebidas e utilizadas para as atividades do negócio da organização (VALENTIM, 2004).

Para que a GI seja efetiva é preciso desenvolver algumas atividades básicas como, por exemplo, a identificação das necessidades informacionais. Para tanto, é necessário realizar o mapeamento e reconhecimento dos fluxos formais de informação, bem como o desenvolvimento de uma cultura organizacional positiva em relação à informação, proporcionando a comunicação informacional eficiente através do uso das Tecnologias de Informação e Comunicação (TIC), com o objetivo de prospectar e monitorar a informação através da coleta, filtragem e tratamento (análise, interpretação, agregação de valor), a fim de comunicá-la eficientemente, por meio da mediação e disseminação, de maneira que seja possível elaborar produtos e serviços informacionais e retroalimentar o ciclo informacional (VALENTIM, 2004).

Gerir informação é decidir o que fazer com base em informação e decidir o que fazer sobre a informação. É ter a capacidade de selecionar entre as informações disponíveis aquela que é relevante para uma determinada decisão, é perceber qual a decisão que interessa para a 
organização (BRAGA, 2000). Sendo assim, a informação, quando apropriada, se transforma no conhecimento dos sujeitos organizacionais que, por sua vez, se transformam nas ações organizacionais, ou seja, é base para desenvolverem suas atividades. A importância da informação em contextos competitivos, e com o qual as organizações se deparam, requer novas formas de gestão organizacional.

A gestão estratégica da informação não apresenta linearidade. Este tipo de gestão pode ser definido como um processo que exige necessariamente a cooperação dos vários setores da organização, pois o ambiente informacional de qualquer organização sofre influências do ambiente de negócio, tanto internamente quanto externamente, seja pela instabilidade do mercado, seja pela acirrada competitividade entre os concorrentes. Assim, exige conhecimento de seus gestores no intuito de perceberem a natureza e intensidade dos fatos que impactam a organização, de modo que se possa realizar 0 realinhamento organizacional frente a um novo contexto (CÂNDIDO; VALENTIM; CONTANI, 2005). A GI é um processo gerencial, visto que "[...] obter informações é realmente uma atividade ininterrupta, não algo que possa ser finalizado [...]. Portanto, o processo mais eficaz é aquele que incorpora um sistema de aquisição continua [...]" (DAVENPORT; PRUSAK, 1998, p.181).

O gerenciamento da informação só é eficiente na medida em que a informação é de fato utilizada. Sendo assim, o uso e o reuso são etapas essenciais da GI. Dessa maneira, destaca-se que a informação é cíclica e reutilizável e, por isso, o ambiente informacional é afetado constantemente.

No Século $X X I$ as organizações têm na informação e no conhecimento subsídio para auxiliar a tomada de decisão, e as transformações em decorrência da globalização são visíveis. Assim, cabe às organizações serem proativas para lidar com clientes, concorrentes e fornecedores, visando gerar diferenciais competitivos para sua atuação. Quanto melhor gerenciada, tratada e organizada a 
informação nos ambientes organizacionais, mais rapidamente a organização poderá tornar-se competitiva no que tange aos seus processos, produtos, serviços etc., proporcionando um melhor posicionamento no mercado em que atua.

Nessa perspectiva, possuir informação sobre o ambiente organizacional, seja interno ou externo, se constitui na base para o desenvolvimento estratégico organizacional, ou seja, é insumo para o desenvolvimento da competitividade organizacional. Ressalta-se que a quantidade de informações produzidas organizacionalmente em âmbito formal e informal, torna o processo de Gl fundamental para a organização, devendo ser eficiente, visto que dinamiza o processo decisório organizacional.

Portanto, o bom gerenciamento e o uso de métodos e técnicas atualizados devem ser uma constante, visto que a organização sofre influência das mudanças do ambiente. As organizações vivenciam constantes mudanças, às vezes profundas, por isso, gerenciar informação é essencial para qualquer tipo de organização. A gestão visa entre outras coisas detectar oportunidades e reconhecer ameaças e, assim, preparar a organização para as turbulências que virão ajustandoa para o impacto positivo ou negativo que possa vir. Complementando esse entendimento, Beuren (2007) afirma que os gestores devem conhecer profundamente a organização onde atua.

Atualmente, muitas organizações desejam melhorar o nível de informação nos diversos setores, sendo assim o fornecimento de informações no processo de Gl é uma preocupação constante dos profissionais responsáveis por essa atividade. Ressalta-se que não há simplicidade na atividade de $\mathrm{GI}$, visto que há uma diversidade imensa de informações que podem subsidiar o gestor a definir, avaliar e executar uma determinada estratégia que viabilize o objetivo e metas organizacionais (BEUREN, 2007). Nesse sentido, a prospecção, o monitoramento e a filtragem do que é relevante são atividades bases da GI. 
A globalização da economia tem acirrado a relação entre as organizações. Assim a competitividade é uma realidade, consequentemente mudanças significativas ocorrem constantemente, isto é, desde mudanças quanto ao modelo de gestão organizacional até mudanças que afetam o desenvolvimento tecnológico, cuja ênfase na qualidade dos processos e produtos, visa a conquistar a satisfação do cliente frente à concorrência (BEUREN, 2007).

A valorização da informação como recurso econômico para a sobrevivência das organizações é fundamental, uma vez que a informação gerada internamente propicia o suporte informativo adequado às diferentes atividades exercidas em seu âmbito. $O$ princípio de valor reside no fato de que a GI competente aumenta o número de decisões mais assertivas, ou seja, podem fortalecer ou não a competitividade organizacional. A Gl explora a interface da informação com a estratégia organizacional, ou seja, a elaboração, execução e avaliação de desempenho. Nessa perspectiva, se constitui em alicerce para os modelos de decisão, para a elaboração de indicadores de avaliação, mensuração de resultados, bem como para diferentes possibilidades de análise de impacto (BEUREN, 2007).

A informação tem a capacidade de reduzir a incerteza organizacional, consequentemente ajuda o gestor a tomar decisões mais acertadas, e seu valor resulta do comportamento da decisão. Desempenha um papel essencial e se constitui em elo para o funcionamento do todo organizacional, ou seja, possuir informações compatíveis com as exigências do ambiente competitivo, certamente, propiciará uma condição diferenciada para a organização, assegurando sua continuidade/manutenção no mercado.

O processo de Gl possui três etapas distintas: planejamento, execução e controle, de modo que as informações são concebidas e comunicadas com base nos princípios, procedimentos e orientações estabelecidos no modelo de gestão da empresa (BEUREN, 2007). 
A informação nunca foi tão importante para a economia de um país, porquanto ela pode ser considerada um dos pilares da estratégia organizacional, cujo objetivo principal é convertê-la em valor para a organização. Uma vez que os processos organizacionais dependem fortemente do conhecimento gerado pelos colaboradores que nela atuam e, principalmente, se considerar que as organizações na sua maioria, não possuem informações consistentes para subsidiar suas decisões estratégicas, conforme explica Beuren (2007, p.65) "[...] saber informar os resultados de ações relevantes, é condição vital num cenário onde a empresa busca uma vantagem competitiva."

A informação é recurso estratégico para auxiliar a tomada de decisão e o gerenciamento da informação proporciona aos gestores planejar-se estrategicamente, isto é, conhecer sua missão, ter uma visão do ambiente no qual estão inseridos, criar habilidades para agregar valor às informações, a fim de transformá-las em conhecimentos necessários, apoiando assim as decisões estratégicas da organização.

É notório que no contexto atual as informações compõem um dos mais valiosos ativos para as empresas, pois elas alimentam o processo de tomada de decisão, por meio da redução da incerteza que, por sua vez, é derivada do uso da informação, ou seja, gerenciar informação implica em verificar as necessidades informacionais e desenvolver as etapas básicas de gestão: coleta, seleção, análise, tratamento, organização, armazenamento, disseminação, uso e reuso da informação.

\section{SETOR TÊXTIL E DE VESTUÁRIO}

A identificação das necessidades de informação do setor industrial é uma preocupação permanente, uma vez que o conhecimento do mercado propicia um melhor reconhecimento das reais necessidades, ameaças e oportunidades. 
Informação, conhecimento, inteligência e tecnologia são fatores fundamentais para o sucesso de cadeias produtivas no mercado globalizado e competitivo no qual a sociedade contemporânea está inserida. Além disso, a sobrevivência das organizações reside na própria capacidade de antecipação às ameaças e oportunidades que surgem no ambiente, ou seja, a competitividade é um diferencial que possibilita às organizações se manterem no contexto em que atuam.

Os fatores mencionados acima vêm sendo considerados cruciais para o desenvolvimento econômico, caracterizado por um ambiente competitivo, globalizado e dinâmico, cujo setor industrial têxtil/vestuário/moda avançou muito nos últimos anos. O Brasil possui, atualmente, produtividade nesse segmento e se aproxima dos níveis internacionais, visto que vem passando por transformações significativas que propiciam essa condição.

Entre os desafios a serem enfrentados, destaca-se o fortalecimento da cadeia industrial, desde a produção da matéria prima até a fabricação e distribuição do produto acabado no mercado, visto que são fatores essenciais para 0 incremento da competitividade, porquanto a abertura comercial e a globalização das atividades econômicas têm introduzido novas formas de cooperação entre as organizações, fomentando a modernização de instalações industriais, terceirizando etapas do processo produtivo para reduzir custos, atuando em arranjos produtivos locais para enfrentar a concorrência externa, entre outros fatores (BRASIL, 2008).

Tais ideais e objetivos competitivos para uma organização são fatores determinantes para o crescimento qualitativo, pois o fato de estar inserida no contexto globalizado exige que obtenha estabilidade e reconhecimento.

O mercado têxtil nacional tem potencial de crescimento, especialmente em virtude da demanda reprimida, conforme explica Gorini (2008, p.19) 
A cadeia produtiva têxtil - reunindo fiação, tecelagem, malharia, acabamento, beneficiamento e confecção vem passando por muitas transformações recentes destacando-se especialmente aquelas relacionadas não apenas as mudanças tecnológicas que permitiram expressivos incrementos de produtividade, mas também a crescente importância, do comércio intrablocos $[\ldots]$.

O panorama mundial evidencia novos padrões de concorrência, baseado não apenas em preços, mas também em qualidade, flexibilidade e diferenciação de produtos, além da própria organização do comércio que procura reunir avanços tecnológicos e de inovação na indústria têxtil.

Quando se compara o crescimento do Brasil ao de outros países que compõem o bloco econômico denominado de 'BRIC' - composto por Brasil, Rússia, Índia e China -, a situação é preocupante, uma vez que o crescimento brasileiro é irrisório em relação a esses países, e o mais preocupante é que esta fase favorável de crescimento econômico pode ter um curto período de duração. Dessa maneira, enquanto o Brasil cresce lentamente, os outros países avançam, ou seja, alguns mercados importantes estão sendo perdidos pelas empresas nacionais (BRASIL, 2008). No entanto, o Brasil pode ser visto como um país recém-formado quando comparado historicamente aos seus concorrentes e, por essa razão, conforme defende Caldas (2006), temse muito a aprender e crescer e, assim, é necessário trabalhar a competitividade brasileira em três etapas: preparação, planejamento e persistência.

Segundo este autor, a preparação é importante porque o Brasil é um país em desenvolvimento e, portanto, está em aprendizado contínuo, ou seja, não há um contexto histórico favorável que sirva como base para a tomada de decisão e o planejamento administrativo. 0 planejamento aliado à criatividade é fundamental para a construção de uma identidade nacional, visando abrir novos caminhos, cumprir metas, reduzir burocracias e estabelecer políticas sólidas. O Brasil, ainda, está em fase de construção de sua própria identidade, tanto no campo 
econômico quanto no político e social. Ele necessita de uma política de desenvolvimento estável, financiamento, cultura, crescimento sustentável, transferência de tecnologia, geração de conhecimentos, política cambial que não sofra depreciação, integração de diversas cadeias produtivas, incentivo à pesquisa e à qualificação de recursos humanos, através de uma maior interatividade entre as universidades e as empresas.

As parcerias e criação de polos e de Arranjos Produtivos Locais (APL) podem ser consideradas um caminho para alavancar o crescimento sustentável do mercado brasileiro, pois as habilidades de planejar, pensar prospectivamente, gerenciar informações, controlar receitas e despesas e essas ações em conjunto tendem a fortalecer o poder de negociação.

O Brasil deve investir em ativos intangíveis: capacitação, valorização de características regionais, visto que a busca de uma identidade nacional e a utilização de design brasileiro como diferencial estratégico tende a fortalecer a competitividade do país, porquanto o "[...] design é percebido como um diferencial que deve ser desenvolvido por sua capacidade de agregar valor aos produtos e as marcas brasileiras." (CALDAS, 2006, p.148), isto é, é necessário que as empresas se preocupem com o panorama global.

A indústria brasileira vem mudando, contudo, há uma grande informalidade. A competitividade da indústria não depende somente da eficiência dos processos produtivos, mas também de qualidade, conforto e sobretudo design em que a inovação é fundamental.

\subsection{Características Gerais do Setor Têxtil e Vestuário}

O Brasil se encontra entre os dez maiores produtores mundiais de fios/filamentos, tecidos e malhas, especialmente de algodão. Neste último segmento - malhas com predominância de algodão - o país é o terceiro maior produtor mundial, somente perde para os Estados Unidos e a Índia (GORINI, 2008, p.26). A Associação Brasileira de Indústrias 
Têxteis (ABIT, 2007) explica que o Brasil é no cenário mundial o sexto maior produtor têxtil, segundo maior produtor de índigo, terceiro maior de malhas, quinto maior de confecção, sétimo maior de fios e filamentos e o oitavo maior produtor de tecidos.

Vale ressaltar que a participação do Brasil no comércio mundial de têxteis hoje é inferior a $1 \%$, sendo a parcela mais relevante das exportações nacionais relacionada ao segmento têxtil, enquanto o confeccionado segmento que mais cresce em termos de valor mundial exportado - ainda representa parcela relativamente pequena das exportações nacionais. (GORINI, 2008, p.24).

Segundo Gorini (2008) o Brasil perde posições em relação ao total mundial quando se leva em conta o consumo, a produção e a capacidade instalada das fibras manufaturadas (artificiais e sintéticas), mercado ainda pouco desenvolvido. De acordo com a ABIT (2007), alguns gargalos prejudicam a sobrevivência das exportações brasileiras como, por exemplo:

- Ausência de parcerias/alianças estratégicas, ausência de redes integradas de empresas tanto no varejo, [...] como na parceria com fornecedores para 0 desenvolvimento conjunto dos produtos, aquisição, conjunta de matéria prima, etapas conjuntas de produção;

- Baixa informatização, ausência de sistemas;

- Dificuldades para produzir em lotes menores e baixa agilidade;

- Comercialização ineficiente, pequena equipe de venda e grande inexperiência no mercado internacional;

- Baixos investimentos para o desenvolvimento de produto de design.

Nessa perspectiva, alianças estratégicas e arranjos produtivos/comercias são fundamentais, visto que no setor têxtil deve-se priorizar: 
- Investimentos;

- Reestruturação;

- Aumento da Qualidade;

- Acordos comerciais e desenvolvimento de novos mercados;

- Formação de consórcios/parcerias voltadas para exportação. (GORINI, 2008, p.43).

Segundo Cobra (2007) os principais países importadores de vestuário e moda são: Estados Unidos, Alemanha, Hong Kong, Reino Unido e Japão, e os principais exportadores de artigos têxteis e de vestuário se encontram na China, Hong Kong, Itália, Alemanha, Estados Unidos. O Brasil aparece nos dois casos na $42^{\circ}$ posição.

\subsection{Moda Como Negócio}

A dinâmica do mundo da moda afeta a indústria têxtil e de vestuário, cujas mudanças impactam em diferentes sistemas econômicos e sociais, pois a moda gera empregos, obriga a renovação constante [geração de inovação], o consumo e a circulação de dinheiro, sendo a indústria que mais sofre e, ao mesmo tempo, a que mais se beneficia dessa dinamicidade proporcionada pelo mercado da moda.

O produto da indústria do vestuário - a roupa -
caracteriza-se pela sazonalidade das tendências e dos
modelos em sua dimensão cultural, decorrente do fato
de se inserir no campo da moda, que reflete as
peculiaridades de determinada época e de determinado
local. Revela-se assim o efêmero da moda que contribui
decisivamente para a expansão do mercado de
determinados segmentos [...]. A dualidade da roupa
enquanto bem econômico e simbólico congregam
informações de diversas áreas, como econômica,
gerencial, do campo da moda e do contexto sócio
cultural. (ANDRADE, 2002, p.40).

Para Vincent-Ricard (1989, p.139) o sistema da moda é uma ordem da qual se faz uma desordem, mas, sobretudo é uma função bem definida, relacionada a ambiguidade de um sistema ao mesmo tempo 
imprescindível e metódico, regular e desconhecido, aleatório e estruturado.

A moda é um contexto gerador de conhecimento, uma fantasia que se dissemina por meio de informações na velocidade da luz, graças à Internet, portanto, as notícias de moda e de inovações tecnológicas alcançam o consumidor em tempo real.

É preciso redinamizar e fomentar a investigação no campo da moda, pois está é um objeto contraditório por excelência, a moda se encontra em um ambiente fortemente influenciado pela mídia, ela "[...] estandardiza e ao mesmo tempo, diferencia, valoriza e enriquece o ego das pessoas." (COBRA, 2007, p.23). A evolução da moda reflete as transformações da sociedade, atualmente ela extrapola a esfera das atividades industriais, isto é, atinge as redes no nível das relações interpessoais, processos complexos, porém, muito útil agora, visto que a moda cria interdependências e necessita de inteligência para que essa indústria possa sobreviver no Brasil e concorrer globalmente.

A moda é composta de grandes e complexas estruturas, ela não é mais um enfeite estético ela modela a sociedade, ela surpreende e possui efeitos ambíguos. O setor de moda tem que reconhecer e observar seu diferencial na unicidade, pois a moda muda incessantemente, mas sua mudança reside na sutileza (LIPOVETSKI, 1989).

O negócio da moda perpassa por áreas de criatividade, produção, administração e marketing, processos estes que devem ser gerenciados efetivamente para fomentar diferenciais para a organização. $O$ mercado de moda vale-se de conhecimentos de psicologia e sociologia, pois visa fascinar, sendo uma atividade multidisciplinar e desafiadora (COBRA, 2007).

A moda é, sobretudo, um negócio, que acompanha a tendência da economia, dos estilos de vida das pessoas, seus comportamentos e principalmente desejos. Há nesse sentido uma integração mundial e, ao mesmo tempo, interdependência de e entre 
mercados [...]. Os acontecimentos influem na cadeia produtiva de negócios da moda de forma tão intensa que fica difícil dizer, sem medo de errar, de que maneira os fatos se sobrepõem, identificando ou criando necessidades de consumo. (COBRA, 2007, p.26).

O ciclo de vida da moda é muito curto e tende a ser cada dia menor, significando que a moda é mais evolucionária do que revolucionária, quebra paradigmas, exerce fascínio, obriga a antecipação e uso constante de informações atualizadas para suprir rapidamente as necessidades e desejos do setor. Nesse sentido, inovar é antecipar soluções e problemas que, ainda, não aconteceram. Desenvolver ideias simples, eficientes e econômicas para acompanhar as mudanças tecnológicas, econômicas e sociais, gerando vantagem competitiva, por meio do conhecimento gerado.

Com a entrada dos produtos importados, principalmente os chineses, tanto no Brasil quanto no mundo, a indústria brasileira perdeu mercado. Por isso, a criatividade, ou seja, design local pode ser considerado uma das principais formas de diferencial competitivo no mercado internacionalizado.

Segundo Cobra (2007) o comércio mundial é largamente impulsionado pelo setor têxtil e vestuário, e é na tecnologia que o profissional de negócios da moda se apoia, visando estimular o consumo através das inovações, por isso mesmo, o investimento em inovação, tecnologia e modernização de maquinário são fundamentais para o processo de crescimento e desenvolvimento do setor.

A moda é hoje um dos temas mais fascinantes porque, por meio dela, podemos analisar inúmeros aspectos de uma cultura. Não é só um mercado, não é só uma questão de consumo que interessa. A moda deixou de ser vista como uma bobagem das mulheres fúteis para ser reconhecida como um importante fenômeno social. Importa como um objeto de conhecimento para os estudiosos e, também, como um elemento de autoconhecimento para os consumidores [...]. É uma tentativa, das pessoas serem "normais" e aceitas, mas também de diferenciação. (COBRA, 2007, p.16). 
É claro que a moda gera negócios, exige e provoca mudanças nos padrões industriais, visto que este segmento quer ser competitivo no cenário atual, e a informação é uma maneira de se obter essa competitividade, ou seja, é matéria-prima para o negócio da moda. A moda como negócio determina o desenvolvimento do setor industrial, portanto é essencial para o setor prospectar tendências e os fenômenos de moda e consumo para oferecer produtos e serviços com diferencial competitivo.

\subsubsection{Informações para negócios em moda}

As transformações que ocorrem em decorrência da globalização exigem postura e atitude proativa. Choo (1998) explica que na busca por informações relevantes a organização deve observar seletivamente a grande quantidade de sinais existentes no ambiente, interpretá-los e oferecê-los em contexto dinâmico como informação voltada ao negócio fomentando o diferencial organizacional.

Para Bio (1996, p.120) as informações voltadas ao negócio visam "[...] alimentar processos de tomada de decisão. As decisões inerentes aos processos de planejamento, ao controle, formulação, ao acompanhamento de políticas e a interpretação de resultados requerem informações adequadas."

A informação pode ser reconhecida como recurso estratégico que proporciona benefícios significativos, desde que seu uso seja eficiente. Para Cronin (1990) a informação tem um valor de uso; valor de troca/mercado; valor de propriedade; valor de restrição, ou seja, possui um valor em cada atividade que está agregada, potencializando o diferencial competitivo da organização que sabe fazer uso da mesma.

As informações sobre produtos, processos e serviços são fundamentais, pois o usuário da informação não é apenas alguém que a consome, mas alguém que a elabora e é capaz de produzi-la (ANDRADE, 2002). 
O processo de entrada no campo da indústria da moda pressupõe ações e práticas informacionais que revelam conhecimentos sobre o universo da indústria e sobre o campo da moda, ou seja, a reunião de um conjunto de informações elaboradas, resultando em novas possibilidades de sentido. A moda deve ter características locais, pois todos os anos o setor têxtil de vestuário e moda vem se fortalecendo, bem como a moda passou a ser vista como arte e como negócio, pois transforma produtos em objetos de desejo que geram capital.

A competição nesse segmento impõe à organização a busca constante pela diferenciação, de modo que é necessário se conscientizar que é preciso investir, cada vez mais, em Pesquisa e Desenvolvimento (P\&D) e na formação continuada do capital humano que atua no setor, uma vez que são essenciais para a efetividade do futuro da organização (CALDAS, 2006).

Atualmente, a comunicação é responsável pela influência de boa parte dos artigos da moda consumidos no mundo, visto que as revistas, os jornais, os filmes, a Internet, as redes sociais, entre outros meios de comunicação, circulam em velocidades tais, que as notícias chegam praticamente na mesma hora (COBRA, 2007).

A moda é um ambiente fortemente influenciado pela mídia, conforme explica Caldas (2006, p.96) "[...] a falta de pesquisa de verdade no caminho fácil da cópia travestida de referência, já se anuncia como o erro fatal de empresas e marcas do século XXI." Complementando, afirma que

[...] um dos principais problemas que afetam tanto o universo empresarial quanto as universidades no Brasil é a ausência de investimento na pesquisa de base, aquela que não é diretamente relacionada a novas tecnologias, ao desenvolvimento de produtos e ao aumento da lucratividade, pela incompreensão do próprio papel que esse tipo de pesquisa desempenha no futuro próximo. (CALDAS, 2006, p.101). 
O fenômeno da moda faz parte de uma dimensão do comportamento coletivo, e se dá pela identificação de padrões ou modelos que se repetem continuamente. Nos "[...] anos de 1990 enquanto a moda brasileira dava saltos qualitativos importantes, uma das batalhas mais travadas pelos atores envolvidos no seu desenvolvimento foi a da legitimação desse campo profissional como 'assunto sério'” (CALDAS, 2006, p.97).

As principais estratégias utilizadas pelos atores envolvidos concentram-se em três aspectos: econômicos, profissionais e culturais, uma vez que a moda é um negócio caracterizado pela alta concorrência, bem como gera capital imensurável. Além disso, destaca-se que uma das principais ferramentas da comunicação de moda é a informação, cujo papel no processo de socialização é fundamental.

\section{CONSIDERAÇÕES FINAIS}

A competitividade do setor de têxtil e vestuário exige dinamicidade, e com base na revisão de literatura é possível inferir que, neste contexto, a informação é indispensável para a competitividade, seja em âmbito estadual, nacional ou mundial, portanto, as organizações devem estar aptas a lidar com a gestão da informação de maneira mais dinâmica, pois a complexidade das informações influi, cada vez mais, no negócio organizacional do setor empresarial.

A análise da literatura embasa a assertiva de que a competitividade organizacional está imbricada aos fazeres da organização, bem como evidencia que possui potencial competitivo imensurável para apoiar o desenvolvimento do setor têxtil e de vestuário, sendo relevante e indispensável o uso da Gl para apoiar as estratégias competitivas deste segmento econômico. A partir da análise teórica de conceitos e definições foi possível obter uma visão aprofundada sobre o objeto e fenômenos desta pesquisa, evidenciando 
que a informação é insumo fundamental para a geração de diferenciais competitivos e, portanto, para a obtenção de competitividade.

A pesquisa teve como principal objetivo realizar um ensaio teórico sobre o potencial da gestão da informação para a geração de diferenciais competitivos para o setor têxtil e de vestuário. Desse modo, pode-se considerar que o objetivo previamente proposto foi atingido, bem como acredita-se que este trabalho contribui para o campo da Ciência da Informação, mais especificamente quanto à discussão da gestão da informação aplicado ao setor têxtil e de vestuário, como também recomenda-se que outros estudos devam ser realizados para 0 aprofundamento desta temática tão importante para este setor econômico.

\section{REFERÊNCIAS}

ASSOCIAÇÃO BRASILEIRA DE INDUSTRIAIS TÊXTEIS - ABIT. Disponível em: <http://www.abit.org.br>. Acesso em: 17 ago. 2007.

ANDRADE, M. E. A. A informação e o campo das micro e pequenas indústrias da moda em Minas Gerais: a entrada no campo da indústria da moda. Perspectiva Ciência da Informação, Belo Horizonte, v.7, n.1, p.39-48, jan./jun. 2002.

BEUREN, I. M. Gerenciamento da informação: um recurso estratégico no processo de gestão empresarial. São Paulo: Atlas, 2007.

BIO, S. R. Sistemas de informação: um enfoque gerencial. São Paulo: Atlas, 1996.

BRAGA, A. A gestão da informação. Millenium Internet, Viseu, n.19, jun. 2000. Disponível em: <http://www.ipv.pt/millenium/19_arq1.htm>. Acesso em: 15 mar. 2008.

BRASIL. Ministério do desenvolvimento, indústria e comércio exterior. Disponível em:

<http://www.aprendendoaexportar.gov.br/inicial/index/html>. Acesso em: 17 ago. 2008.

BUCKLAND, M. K. Information as thing. Journal of the American Society for Information Science (JASIS), v.45, n.5, p.351-360, 1991. 
CALDAS, D. Observatório dos sinais: teoria e prática da pesquisa de tendências. Rio de Janeiro: SENAC, 2006.

CANDIDO, C. A.; VALENTIM, M. L. P.; CONTANI, M. L. Gestão estratégica da informação: semiótica aplicada ao processo de tomada de decisão. DataGramaZero, Rio de Janeiro, v.6, n.3, jun. 2005.

Disponível em:<http://www.dgz.org.br/jun05/Art_03.htm> . Acesso em: 13 de dez. 2008.

CHOO, C. W. A organização do conhecimento: como as organizações usam a informação para criar significado, construir conhecimento e tomar decisões. São Paulo: SENAC, 1998.

CIANCONI, R. Gestão da informação na sociedade do conhecimento. Brasília: SENAI/DN, 1999.

COBRA, M. Marketing e moda. São Paulo: SENAC, 2007.

CRONIN, B. Esquemas conceituais e estratégicos para a gerencia da informação. Revista da Escola de Biblioteconomia da UFMG, Belo Horizonte, v.19, n.2, p.195-220, set. 1990.

DAVENPORT, T.; PRUSAK, L. Ecologia da informação: por que só a tecnologia não basta para o sucesso na era da informação. São Paulo: Futura, 1998.

GORINI, A. P. F. Panorama do setor têxtil no Brasil e no mundo: reestruturação e perspectivas. Disponível em:

<http://www.bndes.gov.br/conhecimento/bnsetr/set1202.pdf>. Acesso em: 13 out. 2008.

LIPOVETSKY, G. O império do efêmero: a moda e seu destino nas sociedades modernas. São Paulo: Companhia das Letras, 1989.

MCGEE, J; PRUSAK, L. Gerenciamento estratégico da informação: aumente a competitividade e a eficiência de sua empresa utilizando a informação como uma ferramenta estratégica. 7. ed. Rio de Janeiro: Campus, 1994.

MORIN, E. O método 3: o conhecimento do conhecimento. Porto Alegre: Sulina/Meridional, 1999.

TARAPANOFF, K. (Org.). Inteligência organizacional e competitiva. Brasília: Ed. UnB, 2001.

TARAPANOFF, K. et al. Sociedade da informação e inteligência em unidades de informação. Ciência da Informação, Brasília, v.29, n.3, p.91-100, set./dez. 2000. 
TRIVIÑOS, A. N. S. Introdução a pesquisa em ciências sociais: a pesquisa qualitativa em educação: o positivismo, a fenomenologia, o marxismo. São Paulo: Atlas,1987.

VALENTIM, M. L. P. Em busca da vantagem competitiva. Londrina: Info Home, 2004. Disponível em: $<$ http://www.ofaj.com.br/colunas_conteudo.php?cod=87>. Acesso em: 13 ago. 2008.

Informação estratégica: insumo para tomada de decisão.

Palavra Chave, São Paulo, n.7, p.5-6, 1994.

Processo de inteligência competitiva organizacional. In: VALENTIM, M. L. P. (Org.). Informação, conhecimento e inteligência organizacional. Marilia: FUNDEPE, 2006. p.9-24.

VICENT-RICARD, F. As espirais da moda. Rio de Janeiro: Paz e Terra, 1989.

\section{Tit/e}

Information management in organizational environments: focus in textile and clothing industry

\section{Abstract}

Introduction: The globalization, competitiveness and the necessity to obtain information directed to business with added value are determining factors for organizations generate competitive advantages. In this context, organizations can be seen as systems that generate, process and apply information that, in turn, can be transformed into strategic actions.

Objective: Displays theoretical reference about the potential of information management as a competitive generator tool for the textile and clothing sector.

Methods: We conducted a theoretical, test and descriptive.

Methods: We carried out a theoretical essay of descriptive exploratory nature focusing on the information management and its contribution to the generation of competitive differentiators.

Results: It is inferred from the literature review, that organizational competitiveness imbricated to the organization doings and has competitive potential immeasurable for supporting the development of textiles and clothing industries, being relevant and necessary to use the information management to support the competitive strategies of these economic sectors.

Conclusions: Based on the analysis of concepts and definitions were obtained insight into the subject, showing that information is fundamental input to generate competitive differentiators and instigates further reflections on the application of information management in industry organizations textile and clothing sectors. 
Keywords: Information management. Organizational competitiveness. Competitive Advantages. Textile and clothing sector. Fashion.

\section{Título}

Gestión de la información en ambientes organizacionales: enfoque en el sector textil y de confección

\section{Resumen}

Introducción: La globalización, la competitividad y la necesidad de obtenerse la información dirigida a los negocios con valor agregado son factores determinantes para las organizaciones generaren diferenciales competitivos. En este contexto, las organizaciones pueden ser vistas como sistemas que generan, procesan y aplican la información que, a su vez, se puede transformar en acciones estratégicas.

Objetivo: Presenta el marco teórico sobre el potencial de la gestión de la información como una herramienta generadora de competitividad para el sector textil y de confección.

Métodos: Se realizó un ensayo teórico, de naturaleza descriptiva exploratorio centrado en la gestión de la información y su contribución a la generación de diferenciales competitivos.

Resultados: Se infiere a partir de la revisión de la literatura, que la competitividad organizacional está incorporada a los haceres de la organización, y tiene potencial competitivo incalculable para apoyar el desarrollo de los sectores textiles y de confección, siendo relevante y necesario el uso de la gestión de la información para apoyar las estrategias competitivas de estos sectores económicos.

Conclusiones: A partir del análisis de los conceptos y definiciones se obtuve comprensión sobre la temática, lo que demuestra que la información es un insumo clave para generar ventajas competitivas provocando nuevas reflexiones sobre la aplicación de la gestión de la información en las organizaciones de la industria textil y de la confección.

Palabras-Clave: Gestión de la información. Competitividad organizacional. Ventajas competitivas. Sector textil y de confección. Moda.

Recebido em: 15/03/2015

Aceito em: 10/09/2015 